\title{
METODOLOGIA PARA CONTROLE DA AGREGAÇÃO TECNOLÓGICA DURANTE O PROCESSO DE INCUBAÇÃO. A EXPERIÊNCIA DA INCUBADORA TECNOLÓGICA
} AGENDE GUARULHOS, BRASIL - 2013

\author{
Devanildo Damião \\ Doutor em Tecnologia Nuclear pela Universidade de São Paulo - USP \\ devan@usp.br (Brasil) \\ Carlos Graça \\ Doutor em Engenharia de Produção pela Universidade de São Paulo - USP \\ c.graca@ig.com.br (Brasil)
}

\begin{abstract}
RESUMO
O sucesso de empresas nascentes nos EUA em setores de alta intensidade tecnológica gerou transbordamentos que mostraram às economias emergentes ser possível acelerar o desenvolvimento a partir da construção local de tais ambientes propícios à inovação. Particularmente, no Brasil, não obstante os avanços de transferência do conhecimento tecnológico produzido e materializado em tais ambientes, ainda estão latentes duas lacunas estruturais neste processo: i) ausência de modelos de gestão, que incorporem as variáveis de impacto no processo de gestão da incubadora; ii) instrumentos que permitam mensurar de forma específica o nível de intensidade tecnológica de cada projeto, considerando a agregação de conhecimentos e aplicação dos mesmos. O presente trabalho oferece um instrumental frente ao segundo desafio, visto que permite mensurar o nível de intensidade tecnológica, o nível de maturidade e competências das empresas e a sua condição de evolução de agregação de conhecimento técnico aplicado ao seu negócio.
\end{abstract}

Palavras-chave: Incubadora; Agregação tecnológica; Inovação; Guarulhos. 


\section{INTRODUÇÃO}

Considerando o crescimento recente do comércio mundial, observa-se que a demanda de produtos de alta intensidade tecnológica cresceu a taxas superiores à demanda por produtos da manufatura Pré- $3^{a}$ Revolução Industrial, proporcionando vantagens econômicas entre os países desenvolvedores de tecnologia, em relação aos imitadores e aos que não são capazes de inovar nem de imitar.

Estas evidências são corroboradas por vários autores, dentre eles (Montobbio \& Rampa, 2005), quando afirmam que os países com oportunidades tecnológicas altas - aqueles que lideram a mudança tecnológica no mundo - apresentam as maiores taxas de crescimento nas exportações.

Tomando por base tal realidade, os países em desenvolvimento estariam limitados, basicamente, a aceitar as oportunidades dos espaços vazios (nichos) de mercado de produtos de baixa intensidade tecnológica (FAPESP, 2010).

Todavia, com o sucesso de empresas nascentes nos Estados Unidos, surgiu a oportunidade de acelerar o desenvolvimento de países em estágios modestos de desenvolvimento, dando margem ao surgimento de ambiente inovadores organizados para empreendedores, tornando-se uma referência e estratégia de políticas públicas para o desenvolvimento acelerado.

Nos Estados Unidos existem 1.115 incubadoras e o sucesso se propagou por todo o mundo, com destaque para o México (191), Canadá (120), e países da Europa e Ásia.

O Brasil possui 384 incubadoras de empresas atualmente, sendo a grande maioria pretensamente de base tecnológica, com 2.640 empresas incubadas que apresentaram faturamento de R\$ 533 milhões em 2011.

Todavia, mesmo considerando avanços inquestionáveis no processo de transferência do conhecimento com base nas iniciativas da ANPROTEC, observam-se duas lacunas estruturais neste processo: i) o desenvolvimento de modelos de gestão, que incorporem as variáveis de impacto no processo de gestão da incubadora; ii) instrumentos que permitam mensurar de forma específica o nível de intensidade tecnológica de cada projeto, considerando a agregação de conhecimentos e aplicação dos mesmos.

Frente a tal realidade, o primeiro desafio foi superado na Incubadora Tecnológica Guarulhos com o programa PPV (Pronto para Viver) (ANPROTEC, 2011), o qual permite o gerenciamento das empresas na incubadora com base em três variáveis: ciclo de vida, nível de maturidade e competências.

Revista de Administração e Inovação, São Paulo, v. 12, n.1, p.227-247, jan./mar. 2015. 
A proposta do presente trabalho é fazer frente ao segundo desafio, com base num instrumento que permite mensurar o nível de intensidade tecnológica, o nível de maturidade e competências das empresas e a sua condição de evolução de agregação de conhecimento técnico aplicado ao seu negócio. A questão de pesquisa situa-se em como desenvolver um instrumento que incorpore variáveis complexas e permita identificar a evolução no processo de incubação, da gestão da Incubadora e da incorporação de conhecimentos ao projeto.

\section{METODOLOGIA}

Dado o problema central e os objetivos deste trabalho, a estratégia metodológica de pesquisa endereçada para responder às questões, possui característica de pesquisa - ação na qual a produção de conhecimento é guiada pela prática -, e os pesquisadores possuem interferência direta na avaliação das ações desencadeadas e nos resultados do trabalho. Neste método de pesquisa, o conhecimento é produzido e a realidade é modificada simultaneamente, cada um ocorrendo devido à ação do outro [OQUIST, (1978); THIOLLENT (2007)].

Considerando que o sistema PPV, criado pelos pesquisadores, define a realidade de gestão da incubadora, e o ambiente da incubadora é formado por um grupo de empreendedores que atuam para melhorar a racionalidade e o entendimento de suas práticas, existe estreita relação da ação com a resolução de um problema coletivo no qual interagem pesquisadores "versus" empreendedores.

Desta forma, dada a interatividade dos pesquisadores na vida presencial dos empreendedores ao longo do processo de incubação, o pesquisador observa, formula e desenvolve estratégias de gestão e tecnológicas, que atuam no objeto (empreendimento) estabelecendo-se uma cooperação entre pesquisador e pesquisado.

Inserido nesse contexto de construção da prática de conhecer para atuar, propondo soluções e aprendendo com a ação, a estrutura que irá delinear a evolução de agregação tecnológica das empresas incubadas está alicerçada nas seguintes variáveis:

(1) Nível de Maturidade e Competências, que serão determinadas pela aplicação do sistema PPV (programa de gestão da Incubadora), que contempla em cada uma de suas cinco fases, atividades na forma de palestras, workshops, feiras, reuniões, e produtos específicos (técnicos e econômicos) relacionados ao empreendimento.

Revista de Administração e Inovação, São Paulo, v. 12, n.1, p.227-247, jan./mar. 2015. 
(2) Intensidade Tecnológica que será balizada pela classificação da OCDE aplicada às empresas da Incubadora tecnológica Agende Guarulhos, tomando por base o seu tipo de indústria.

A terceira variável, (3) Agregação de Tecnologia será determinada pela aplicação de um questionário, desenvolvido pelos atores, que posiciona o nível de conhecimento agregado que cada projeto incorporou. Cumpre destacar que esta variável é impactada pelos diferentes segmentos tecnológicos, os quais apresentam diferentes modelos de evolução.

Para obtenção dos resultados foi selecionada uma amostra representativa das empresas incubadas na Incubadora com a aplicação de questionários diretos, que incorporaram as dimensões que evidenciam a evolução do produto/processo desenvolvido.

Para a construção do modelo estruturante de avaliação de agregação de conhecimentos em incubadoras de empresas de base tecnológica, as fontes primárias utilizadas nesta pesquisa para a coleta dos dados foram: entrevistas seguidas de questionário semiestruturado com representantes das startups da incubadora de Guarulhos.

Quanto aos conceitos apresentados e discutidos neste trabalho, os mesmos foram desenvolvidos a partir de pesquisa na literatura especializada da qual surgiram ideias que proporcionaram a idealização de um modelo estruturante de métricas que vai ao encontro para a questão central de pesquisa e aos objetivos propostos.

\section{REVISÃO TEÓRICA}

As variáveis do modelo em seu sentido estruturante são: Intensidade Tecnológica; Competência; Maturidade; e Agregação Tecnológica.

\subsection{Intensidade Tecnológica}

A OCDE (1997) (Organisation for Economic Cooperation and Development - Science et Technologie et Industrie - Tableau de Bord d'Indicateurs), desenvolveu uma metodologia que possibilitou classificar os setores industriais por intensidade tecnológica, conforme o seu nível relativo de dispêndio em atividades de pesquisa e desenvolvimento (P\&D) incorridas na fabricação de seus produtos. 
Nesta metodologia, o indicador de intensidade tecnológica expressa o esforço (dispêndio) econômico realizado pelas empresas em $\mathrm{P} \& \mathrm{D}$, e pode ser obtido através de diferentes bases (Dispêndio em $\mathrm{P} \& \mathrm{D} /$ produção; $\mathrm{P} \& \mathrm{D} /$ valor adicionado ou $\mathrm{P} \& \mathrm{D} /$ receita da empresa). Foi este indicador que a OCDE utilizou para classificar os setores industriais em quatro grupos distintos de intensidade tecnológica conforme segue:

$>$ Alta Intensidade Tecnológica: setores aeroespacial; farmacêutico; de informática; eletrônica e telecomunicações.

> Média-Alta Intensidade Tecnológica: setores de material elétrico; veículos automotores; química, excluído o setor farmacêutico; ferroviário e de equipamentos de transporte; máquinas e equipamentos.

$>$ Média-Baixa Intensidade Tecnológica: setores de construção naval; borracha e produtos plásticos; coque, produtos refinados de petróleo e de combustíveis nucleares; outros produtos não metálicos; metalurgia básica e produtos metálicos;

> Baixa Intensidade Tecnológica: outros setores e de reciclagem, madeira, papel e celulose; editorial e gráfica; alimentos, bebidas e fumo; têxtil e de confecção, couro e calçados.

Depreende-se que conforme a estrutura de indústria (concorrência perfeita, monopólio, oligopólio e concorrência monopolística), o indicador proposto pela OCDE tende a variar consideravelmente, pois os produtos em cada tipo de indústria diferem na sua conformidade e complexidade estrutural, o que leva a estágios diferenciados de contribuição da ciência para a tecnologia.

Por exemplo, a indústria farmacêutica, a de computação, a eletrônica, a de instrumentação e a aeroespacial (estruturas em oligopólio e monopólio) têm uma contribuição da ciência para a tecnológica muito superior à de setores das indústrias de concorrência perfeita e concorrência monopolística, segmentos mais próximos da indústria tradicional (Furtado \& Camillo, 2008).

Neste trabalho, a escala de intensidade tecnológica proposta pela OCDE no desenvolvimento de produtos serve para no início do processo enquadrar a startup ao ingressar na incubadora, e, posteriormente, ao longo do processo de incubação, junto com as variáveis competência e maturidade formar o grid de agregação tecnológica que o projeto da startup vai incorporando ao longo do seu desenvolvimento. 


\subsection{As Variáveis Competência e Maturidade}

Conforme proposta metodológica, o valor das variáveis competência e maturidade é determinado pela aplicação do sistema PPV - Programa de Gestão da Incubadora, que desenvolve e controla atividades orientadas à formação de competências e emprega mecanismos para avaliar a maturidade da empresa nascente.

Apresenta-se a seguir o entendimento das variáveis enquanto conceito e em seguida o processo de medição das variáveis pelo sistema PPV.

\subsubsection{Competência}

Conforme destacado em Damião \& Graça (2011), na parte final do século XX, o conceito competência tornou-se um importante vetor para a criação de diferenciais competitivos tanto no plano do indivíduo, de grupos, de organizações e até mesmo de países.

Nos referidos autores, competência pode ser entendida como um saber agir responsável e reconhecido pela ciência, que implica mobilizar, integrar, transferir conhecimentos, recursos e habilidades que agreguem valor econômico à organização e valor social ao individuo.

Como neste trabalho estamos tratando da agregação de tecnologia em incubadoras, e em tais ambientes a empresa incubada e o empresário empreendedor podem ser pensados como uma única pessoa, o conceito competência priorizará competências no nível da pessoa, e a partir de Zarifian (2001); a competência profissional e organizacional.

Este recorte, centrado no indivíduo e organização torna-se consistente com a questão central, pois ao integrar conhecimentos, habilidades e atitudes ou práticas comportamentais que permitirão o desenvolvimento do projeto, promove o refinamento do indivíduo e a sustentabilidade da empresa nascente no seu ambiente de atuação.

Trazendo para a discussão o Sistema de Gestão PPV, modelo de gestão da incubadora, neste, a capacitação do empreendedor (desenvolvimento de competências) ocorre durante o processo de incubação no qual tramita o ciclo de vida da empresa na incubadora entendido como um processo de aprendizagem formado por etapas conforme segue: Amamentação, Primeiros passos, Articulando conhecimentos, Caminho da escola e Pronto para viver.

Vale lembrar que o Sistema de Gestão PPV oferece capacitações (meios) - infraestrutura física, tecnológica e de gestão - para o desenvolvimento de competências (capacidades, habilidades e atitudes) dos empreendedores tornando-os aptos a transformar ciência e tecnologia em resultado.

Revista de Administração e Inovação, São Paulo, v. 12, n.1, p.227-247, jan./mar. 2015. 
Para tanto, em cada uma das fases, a incubadora, além de disponibilizar ao empreendedor apoios tecnológicos, financeiros, mercadológicos, empreendedores, de captação de recursos, e outros, desenvolve ainda atividades (palestras, encontros, seminários, workshops, cursos), criando as condições estruturantes básicas e a componente motivação que desencadeia a construção de um ambiente propício à inovação.

Para que todo esse processo atinja os resultados esperados, isto é, para que a tecnologia se materialize, são exigidos, ao término de cada fase, produtos circunscritos do Plano de Negócios em consonância com as fases do sistema de gestão PPV conforme revelado na tabela abaixo.

Entenda-se a variável competência como representativa dos produtos circunscritos ao Plano de Negócios, devidamente avaliados (quantitativa e qualitativamente) pelo comitê técnico da incubadora.

Tabela 1 - Fases e Produtos contemplados no Sistema PPV

\begin{tabular}{|c|c|}
\hline FASES & PRODUTOS / FOCO \\
\hline (1) AMAMENTAÇÃO & $\begin{array}{l}\text { Plano de Negócios: Estruturação Inicial da Empresa e Visão } \\
\text { do seu Negócio. }\end{array}$ \\
\hline (2) PRIMEIROS PASSOS & $\begin{array}{l}\text { Relatório de Gestão: Estruturar o produto ou serviço da } \\
\text { empresa, estruturar os processos da empresa e desenvolver } \\
\text { habilidades pessoais e empreendedoras. }\end{array}$ \\
\hline (3) ARTICULANDO & $\begin{array}{c}\text { Projeto de Fomento: Buscar parcerias e financiamento para } \\
\text { os negócios e desenvolver, e como firmar parcerias } \\
\text { estratégicas. }\end{array}$ \\
\hline $\begin{array}{l}\text { (4) CAMINHO DA } \\
\text { ESCOLA }\end{array}$ & $\begin{array}{l}\text { Planejamento Estratégico: Desenvolver estratégia para } \\
\text { competir no mercado; }\end{array}$ \\
\hline $\begin{array}{l}\text { (5) PRONTO PARA } \\
\text { VIVER }\end{array}$ & Plano Consolidado - atuação fora da Incubadora. \\
\hline
\end{tabular}

Fonte: Damião \& Graça - Sistema PPV (2011) 


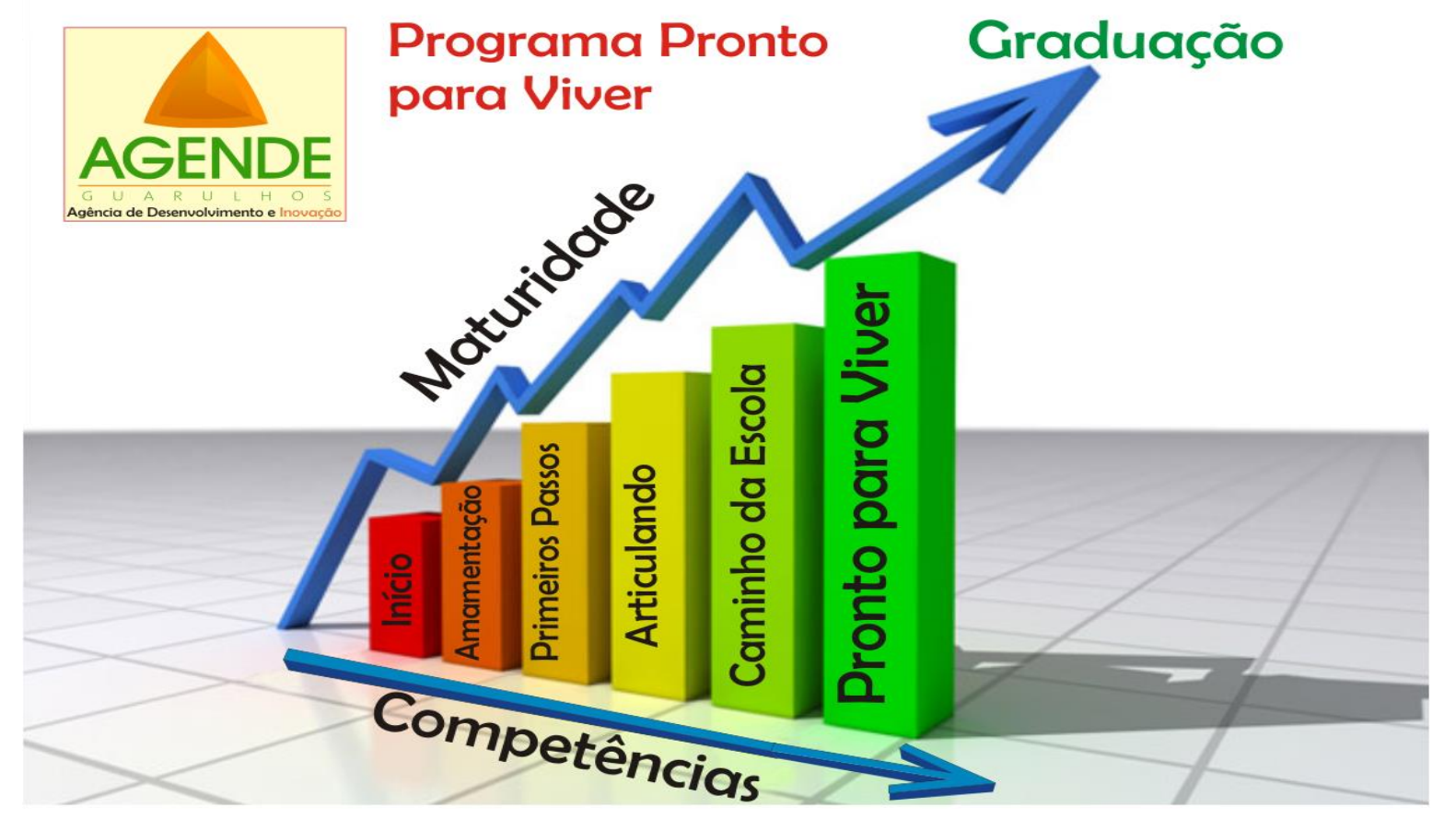

Figura 1: Modelo do Programa PPV.

\subsubsection{Maturidade}

Quanto à variável maturidade, na sua caracterização, os autores deste artigo tentaram buscar na literatura corrente a maturidade enquanto conceito, todavia, as pesquisas revelaram que o uso do termo é muito disperso e o conceito não consolidado globalmente.

Não obstante a adversidade no uso do termo, o enfoque de Fiates et all (2008), para os quais a maturidade tecnológica da empresa está ligada à capacidade desta desenvolver e gerenciar projetos em termos de metodologia e gestão estratégica é referência na construção de nosso conceito.

Assim pensando, para avaliar a maturidade das tecnologias em evolução, e consequentemente do desenvolvimento do projeto, o sistema PPV (sistema de gestão da incubadora) capta esta realidade de forma indireta ao exigir que o empreendedor tenha visão do seu negócio e de todos os elementos de impacto, identificando clientes, fornecedores e processos principais, explicitados nos produtos desenvolvidos.

Desta forma, neste trabalho, considerando que o ciclo de vida da empresa vai mobilizando conhecimento, e este desenvolvendo competências, a maturidade do empreendedor (empresa nascente) corresponde ao status de prontidão tecnológica (capacidade de materializar conhecimento) demonstrado pela evolução do projeto em relação à fronteira tecnológica (escala OCDE) de seu segmento econômico. 


\subsubsection{Agregação Tecnológica}

Em Gehany (1998), a agregação de tecnológia é um o fenômeno que pode ser entendido como a evolução do "saber-fazer" em consonância com as mudanças que ocorrem no desenvolvimento do conhecimento requerido para empreender determinado projeto.

Do trabalho de Verri (2008) "O ciclo de vida dos inventos e das inovações, transições e seus aprontamentos", capta-se o status de prontidão tecnológica (capacidade, agilidade e coordenação imediata para aplicação do conhecimento tecnológico) como um processo que emana de um fluxo contínuo de agregação de tecnologias, resultantes da materialização de múltiplos conhecimentos sobre determinado fenômeno.

O fluxo de agregação e a evolução do "saber-fazer", em Bohn (2005) passam por vários estágios definidos por alguma medida contemplativa de "arte ou ciência". Na arte, o "saber-fazer" advém das habilidades do indivíduo (fazer algo de uma maneira "sui generis"), e no qual o conhecimento é informal e tácito. Já no uso moderno da ciência (o conhecimento é sistematizado e codificado), tem-se através de modelos científicos o "saber-porque" as coisas acontecem, isto é, temse a cientificidade do "saber-fazer".

Para este autor, o conhecimento sobre as variáveis de um fenômeno tem vários possíveis graus, e cada grau (estágio) descreve o conhecimento específico sobre as variáveis de entrada, as de processo e a previsibilidade e consistência de resultados.

Para ilustrar o fato, reproduzimos na tabela abaixo os estágios de conhecimento tecnológico compreendidos entre completa ignorância (estágio 1) e completo entendimento (estágio 8). Entre esses extremos, o conhecimento e domínio sobre as variáveis de um processo tecnológico passam por vários graus possíveis.

Vale destacar que os estágios a partir da origem (completa ignorância) são cumulativos na agregação de conhecimento, representando, portanto, "nós" de um processo evolutivo em direção à ciência, na materialização de conhecimentos e agregação de tecnologias. 
Tabela 02 - Estágios de Conhecimento da arte em direção à "ciência"

\begin{tabular}{|c|c|c|c|}
\hline Estágio & Nome & Aspectos & Tipo de conhecimento \\
\hline 1 & Inconsciência & Leigo & Inexistente \\
\hline 2 & Consciência & Arte & Tácito \\
\hline 3 & Mensurável & Pré-Tecnológico & Explicito \\
\hline 4 & Mensurável / Média & $\begin{array}{c}\text { Pré-Método } \\
\text { científico }\end{array}$ & $\begin{array}{c}\text { Explícito e incorporado em } \\
\text { máquinas }\end{array}$ \\
\hline 5 & Mensurável c/Precisão & $\begin{array}{c}\text { Capacidade de } \\
\text { Processo }\end{array}$ & Ferramentas de Precisão \\
\hline 6 & Qualificação Processo & Tradeoffs & Cálculo numérico \\
\hline 7 & Modelo Científicos & Ciência & Equações e algoritmos \\
\hline 8 & Complete knowledge & Nirvana & Infinito \\
\hline
\end{tabular}

Fonte: adaptada a partir de Bohn (2005).

\subsubsection{Adaptação da escala de Bohn para empresas startups}

Tendo como referência a escala de conhecimento tecnológico de Bohn, pretende-se a partir dela modelar estágios compatíveis com o desenvolvimento de startups durante o seu processo de incubação, numa IBT - Incubadora de Base Tecnológica.

Para tanto, conforme mostrado acima, a tabela tem oito níveis de conhecimento orientados em direção à ciência, e, como tal, refletem a estrutura geral do conhecimento sobre determinada tecnologia. Todavia, analisando tais critérios para aplicação na incubadora, de forma a aferir a agregação de tecnologia em empresas iniciantes modelou-se para quatro níveis pelas seguintes razões:

O $1^{\circ}$ estágio (completa ignorância) foi identificado de forma excludente no processo de seleção, visto que a submissão, avaliação e seleção da startup é feita pelo Comitê Técnico da Incubadora, e na sua avaliação já são contemplados os aspectos de viabilidade técnica, estratégica, econômica e legal.

Também os últimos três níveis 6,7 e 8 [6 (qualificação de processos para reduzir custos - tradeoffs), 7 (modelo científico de processos) e 8 (estágio nirvana (onisciência)] foram abandonados, por estarem ligados a estágios de conhecimento mais avançados, quando a startup já se encontra fora da incubadora.

Foram então selecionados os estágios 2 a 5 por apresentarem conteúdos de conhecimento compatíveis com o perfil de competências requerido no desenvolvimento de startups ao longo do processo de incubação.

\section{• Estágio "Conscientização"}

Neste estágio, o conhecimento formal é incipiente, e prevalece a intuição ancorada no conhecimento de senso comum. As variáveis de processo começam a ser reconhecidas, mas falta 
domínio sobre elas e seus relacionamentos. Neste nível desenvolve-se a P\&D necessária para transformar dados (variáveis) em informação (relevância da variável).

\section{- Estágio 2 Know-How (Sabe-Fazer)}

As variáveis e sua relevância são reconhecidas e empreende-se pesquisa para a comprovação da viabilidade e praticidade da tecnologia de projeto. Neste nível começam a ser identificados aspectos importantes no desenvolvimento da tecnologia, mas "a aplicação é ainda especulativa", não há prova experimental ou uma análise detalhada para apoiar o conceito.

\section{- Estágio 3 Know-Why (Entendidas as relações de causa-efeito)}

Os aspectos (variáveis de processo) não são necessariamente precisos (pré-método científico). Esta fase caracteriza-se pelo Desenvolvimento da Tecnologia (invenção) na sua concepção técnica e de mercado. Neste estágio dá-se a validação do projeto na sua aplicação formulada através da prova-deconceito.

\section{- Estágio 4. Take care (Capacidade de operações)}

Controle sobre as variáveis de processo com precisão através de múltiplos valores (ferramentas e serviços técnicos especializados). Demonstração da aplicação da tecnologia (demonstração da operacionalidade e da funcionalidade do protótipo).

Tabela 3 - Matriz de avaliação do conhecimento tecnológico

\begin{tabular}{|c|c|c|c|c|}
\hline Variáveis & $\begin{array}{c}\text { Domínio de } \\
\text { Processo }\end{array}$ & $\begin{array}{l}\text { Domínio de } \\
\text { Produto }\end{array}$ & $\begin{array}{c}\text { Extensão do } \\
\text { Conhecimento }\end{array}$ & $\begin{array}{c}\text { Estilo de } \\
\text { Liderança }\end{array}$ \\
\hline $\begin{array}{l}\text { 1. Consciência, fase de } \\
\text { Identificação } \\
\text { CONSCIENTIZAÇÃO }\end{array}$ & $\begin{array}{l}\text { Os processos } \\
\text { necessários são } \\
\text { conhecidos? }\end{array}$ & $\begin{array}{l}\text { Existe estratégia } \\
\text { de como } \\
\text { materializar a } \\
\text { ideia? }\end{array}$ & $\begin{array}{l}\text { O conhecimento } \\
\text { está na cabeça do } \\
\text { empreendedor? }\end{array}$ & $\begin{array}{l}\text { O entendimento do } \\
\text { líder quanto à } \\
\text { necessidade e à } \\
\text { relevância do } \\
\text { trabalho em equipe } \\
\text { mostra-se claro? }\end{array}$ \\
\hline $\begin{array}{l}2 . \quad \text { Identifica, mede e } \\
\text { controla } \\
\text { KNOW } \mathrm{HOW}\end{array}$ & $\begin{array}{l}\text { Os processos estão } \\
\text { descritos e } \\
\text { mapeados. }\end{array}$ & $\begin{array}{l}\text { Os recursos para } \\
\text { desenvolver o } \\
\text { produto são } \\
\text { controlados? }\end{array}$ & $\begin{array}{c}\text { Existe a descrição } \\
\text { do conhecimento } \\
\text { em algum lugar } \\
\text { (Manuais)? }\end{array}$ & $\begin{array}{c}\text { Existe equipe } \\
\text { definida e critérios } \\
\text { de seleção? }\end{array}$ \\
\hline $\begin{array}{l}\text { 3. Identifica, } \\
\text { Padroniza e Melhora. } \\
\text { KNOW WHY }\end{array}$ & $\begin{array}{l}\text { Existem políticas e } \\
\text { aplicações de } \\
\text { melhorias de } \\
\text { processos }\end{array}$ & $\begin{array}{c}\text { Existem padrões e } \\
\text { controle sobre a } \\
\text { capacidade de } \\
\text { produção, mesmo } \\
\text { em escala } \\
\text { experimental? }\end{array}$ & $\begin{array}{l}\text { A maioria do } \\
\text { conhecimento da } \\
\text { empresa nascente } \\
\text { (startup) está } \\
\text { codificada? }\end{array}$ & $\begin{array}{c}\text { Existem rotinas e } \\
\text { liderança } \\
\text { consolidada? }\end{array}$ \\
\hline
\end{tabular}

Revista de Administração e Inovação, São Paulo, v. 12, n.1, p.227-247, jan./mar. 2015. 


\begin{tabular}{|c|c|c|c|c|}
\hline Variáveis & $\begin{array}{l}\text { Domínio de } \\
\text { Processo }\end{array}$ & $\begin{array}{l}\text { Domínio de } \\
\text { Produto }\end{array}$ & $\begin{array}{c}\text { Extensão do } \\
\text { Conhecimento }\end{array}$ & $\begin{array}{c}\text { Estilo de } \\
\text { Liderança }\end{array}$ \\
\hline $\begin{array}{l}\text { 4. Identifica, } \\
\text { Controla, padroniza, } \\
\text { melhora e replica. } \\
T A K E \text { CARE }\end{array}$ & $\begin{array}{c}\text { Existe certificação } \\
\text { no que tange aos } \\
\text { processos. }\end{array}$ & $\begin{array}{c}\text { Existe o } \\
\text { conhecimento de } \\
\text { como ampliar a } \\
\text { escala e os meios } \\
\text { para tal? }\end{array}$ & $\begin{array}{l}\text { Existem normas de } \\
\text { gestão? }\end{array}$ & $\begin{array}{l}\text { Existem modelos de } \\
\text { trabalho para } \\
\text { incentivar a troca de } \\
\text { conhecimentos e } \\
\text { experiências entre } \\
\text { colaboradores } \\
\text { diretos e indiretos e } \\
\text { demais } \\
\text { stakeholders? }\end{array}$ \\
\hline
\end{tabular}

Fonte: Construção própria.

\subsection{Subsídios para avaliação}

\subsubsection{Domínio de Processos}

O conhecimento da empresa iniciante sobre seus processos pode variar de condições muito primárias (básico) até estágios muito formais e precisos (modelos matemáticos), [Gehany (1998); Bohn (2005); Verri (2008)].

Os referidos autores colocam que um processo tem entradas, saídas e variáveis de estado que caracterizam o que está acontecendo lá dentro.

Dentro dessa perspectiva, entenda-se neste trabalho o domínio de processos determinado pela forma como as atividades são executadas (informal ou formal?), como a tecnologia é entendida (Know-how or know-why), e a qualidade dos resultados obtidos (aleatória ou padronizada?). Tais questionamentos exigem da startup as seguintes respostas:

$>$ Os processos necessários são conhecidos?

$>$ Os processos estão descritos e mapeados?

$>$ Existem políticas de melhorias de processos?

$>$ Existe certificação no que tange aos processos?

\subsubsection{Domínio de Produto}

O produto começa pela ideia (pensar coisas novas), condição que leva à pesquisa (desenvolver conhecimento sobre), para empreender criação (mostrar que pode ser feito).

Como produto é resultado, este ciclo deve permear necessidades e requisitos do mercado, arquitetura (layout), componentes (conformidade), normalização (ambiente), riscos (tecnológico, econômico e financeiro), aspectos da produção (Slack, 1997).

Assim pensando, qual é o estágio atual da startup sobre tais quesitos? 
$>$ Existe estratégia para materializar a ideia?

$>$ Os recursos para desenvolver o produto são controlados?

$>$ Existem padrões e controle sobre a capacidade de produção, mesmo em escala experimental?

$>$ Existe o conhecimento de como ampliar a escala e os meios para tal?

\subsubsection{Localização do conhecimento}

Entendendo o conhecimento como "o saber" sobre determinada realidade, neste trabalho a realidade em questão está circunscrita a processos e produto. A pergunta chave é:

Para executar determinada atividade a startup empreende um "saber-fazer" tácito ou a atividade é executada através de conhecimento organizado (saber-fazer) explícito?

Esta indagação torna-se relevante, pois conforme NONAKA e TAKEUSHI (1997, p. 63), o conhecimento tácito é dificil de ser articulado e está ligado ao indivíduo, já o explícito pode ser articulado na linguagem formal, e permite tanto em produtos quanto em processos de padronização, previsibilidade e consistência de resultados.

Questionamentos sobre o conhecimento em produtos e processos:

$>$ O conhecimento é tácito e está na mente do empreendedor?

$>$ Existe a descrição do conhecimento em manuais?

$>$ A maioria dos conhecimentos está codificado?

$>$ Existem normas de gestão do conhecimento?

\subsubsection{Papel da Liderança}

Um líder tem como principal função a geração da mudança, com suas ações pautadas sobre três pilares fundamentais: estabelecer a direção estratégica da empresa, comunicar essas metas aos recursos humanos e motivá-los para que sejam cumpridas.

Para tanto, tipos de poder e autoridade, estilo pessoal do líder, inter-relações sociais, necessidade de alcançar objetivos corporativos, dentre outros, são aspectos importantes destacados no papel da liderança.

$>\mathrm{O}$ entendimento do líder quanto à necessidade e à relevância do trabalho em equipe mostra-se claro?

$>$ Existe equipe definida e critérios de seleção?

$>$ Existem rotinas e liderança consolidada?

Revista de Administração e Inovação, São Paulo, v. 12, n.1, p.227-247, jan./mar. 2015. 
D Existem modelos de trabalho para incentivar a troca de conhecimentos e experiências entre colaboradores diretos e indiretos e demais stakeholders?

\section{ESTUDO DE CASO - INCUBADORA TECNOLÓGICA AGENDE GUARULHOS}

\subsection{Caracterização das empresas pesquisadas}

Passa-se a descrever os resultados da pesquisa relativa à agregação tecnológica em incubadoras, tendo como espectro a experiência vivida na IBT de Guarulhos no início do ano de 2013. Como na ocasião a incubadora contava com 30 empresas, esta amostra corresponde a 16,6\% do universo.

DNA Express - Empresa do setor farmoquímico que usa tecnologia pioneira no Brasil na produção de DNA sintético e biologia molecular. Tem alto investimento em pesquisa e desenvolvimento (P\&D) contribuindo também com o seu produto para o desenvolvimento da $\mathrm{P} \& \mathrm{D}$ em universidades pelo Brasil. A DNA Express é considerada uma empresa de alta tecnologia pelos critérios da OCDE e faz parte de uma cadeia produtiva em expansão no país, que é o ramo da farmacologia, onde se enquadram os insumos farmacêuticos, a biologia molecular, biofarmacêutica, química de produtos naturais e produtos sintéticos.

A empresa é gerenciada pelo empresário João Marcos M. Mercado, que é formado em Ciências Biomédicas pela UNIFESP e tem mestrado pelo Instituto de Química da USP.

PRLGrill - O diferencial do produto da empresa é a atuação ambientalmente responsável, tem como produto uma churrasqueira que não faz fumaça e usa uma pequena quantidade de carvão, conservando o calor para o churrasco e não para o ambiente. É ideal para prédios residenciais, proporcionando um grande mercado a ser explorado. Porém, o mercado da empresa não se limita apenas aos prédios, estende-se também a casas, restaurantes, lojas, etc.

O projeto foi desenvolvido pelo empresário Paulo Roberto Lazarin, administrador, que depois de criar o seu produto inovador e fazer uma pesquisa de mercado, viu que seu negócio era viável e decidiu constituir o seu negócio com a ajuda da Incubadora Guarulhos.

Micro Injeção - Tecnologia em micro injeção de materiais plásticos, garantindo criação e inovação ilimitadas na produção. Este tipo de tecnologia tem um custo mais baixo, processo de produção mais rápido e nível de precisão mais alto.

Revista de Administração e Inovação, São Paulo, v. 12, n.1, p.227-247, jan./mar. 2015. 
A empresa pode atingir diversos setores da economia, tais como: indústria eletrônica, área médico hospitalar, farmacêutico, ótico, automobilístico, moveleiro, automação industrial e setores diversos.

O fundador da empresa é Fabiano Durães Falcone, que tem formação em administração e tecnologia de produção em injeção de plásticos. O empresário tem grande vivência no setor de plástico, pois atua no segmento desde o ano de 1996 com outra experiência empresa na para fabricação de soluções em plásticos para o setor moveleiro.

Ser Leve - A empresa com o suporte em transferência de tecnologia da Embrapa (Empresa brasileira de pesquisa agropecuária) passou a produzir no Brasil, com resultados satisfatórios, grãos de origem andina, tais como a quinoa e o amaranto.

O mercado de atuação é bastante amplo e tem demanda crescente, devido aos benefícios que esses tipos de grãos trazem à saúde e a preocupação com a alimentação que boa parte da população passou a ter.

A empresa foi fundada pelo Sr. Marcel Sanchez que, aproveitando de um nicho de mercado, trocou o ramo de elétrica e transporte pelo ramo de agronegócios, passando a cultivar grãos de quinoa e amaranto no Brasil.

MS Ferramentaria - Empresa que desenvolve suportes especiais para uso hospitalar, linha de acessórios para uso em clínicas médicas e odontológicas e na área de mecânica de projetos e construção de máquinas e dispositivos e automação industrial. A empresa, cujos fundadores são Wallace Santim e Marcos Moraes, faz projetos personalizados para a área odontológica e de elétrica, atendendo de universidades a empresas do setor automobilístico. A empresa se desenvolveu e ampliou sua lista de clientes. Hoje em dia desenvolve produtos inovadores, formando parcerias importantes com a USP e a FDTE (Fundação para o Desenvolvimento Tecnológico da Engenharia).

\section{APRESENTAÇÃO E DISCUSSÃO DOS RESULTADOS DA PESQUISA}

A tabela 4 mostrou uma matriz de correlação entre níveis de conhecimento de Bohn e estágios do sistema PPV, e a tabela 5 agrega a matriz de agregação tecnológica criada a partir das correlações da tabela 4 .

Revista de Administração e Inovação, São Paulo, v. 12, n.1, p.227-247, jan./mar. 2015. 
Tabela 4- Matriz de agregação tecnológica

\begin{tabular}{|c|c|c|c|}
\hline Empresas & Intensidade Tecnológica & $\begin{array}{l}\text { PPV } \\
\text { Fases }\end{array}$ & Agregação Tecnológica \\
\hline DNA EXPRESS & Alta Intensidade & Caminho da Escola & $\begin{array}{c}\text { Score - } \mathbf{3 , 3} \\
\text { Know why avançado }\end{array}$ \\
\hline PRLGrill & Média-baixa & Caminho da Escola & $\begin{array}{c}\text { Score - 3,2 } \\
\text { Know why - moderado }\end{array}$ \\
\hline Micro Injeção & Média Baixa & Primeiros Passos & $\begin{array}{c}\text { Score - 1,3 } \\
\text { Conscientização- } \\
\text { avançado }\end{array}$ \\
\hline Ser Leve & Baixa Intensidade & $\begin{array}{l}\text { Articulando } \\
\text { Conhecimentos }\end{array}$ & $\begin{array}{c}\text { Score }-1,2 \\
\text { Conscientização } \\
\text { moderado }\end{array}$ \\
\hline MS Ferramentaria & Média baixa & $\begin{array}{c}\text { Articulando } \\
\text { Conhecimentos }\end{array}$ & $\begin{array}{c}\text { Score }-3,1 \\
\text { Know why incipiente }\end{array}$ \\
\hline \multirow[t]{6}{*}{ Cor } & Empresas & Raio & $\begin{array}{l}\text { Nível } \\
\text { Agregração }\end{array}$ \\
\hline & 1. DNA & 2,3 & 3,3 \\
\hline & 2. $\quad$ Prgrill & 2,2 & 3,2 \\
\hline & 3. $\quad$ Plastimobile & 1,3 & 1,3 \\
\hline & 4. Ser leve & 1,2 & 1,2 \\
\hline & 5. MS Ferramentaria & 2,1 & 3,1 \\
\hline
\end{tabular}

Fonte: Construção própria.

Desta forma, na Tabela 5, a DNA EXPRES (indústria farmacêutica) insere-se na taxonomia da OCDE como de alta intensidade tecnológica. No sistema PPV está pontuada no estágio "Caminho da Escola" e atingiu uma pontuação de Agregação Tecnológica $(3,3)$.

Na matriz de avaliação do conhecimento tecnológico (tabela 4) está na posição know why numa perspectiva avançada, apresentando processo e produto controlados e avanços em relação à sistematização dos conhecimentos e desenvolvimento de lideranças, apesar de apresentar lacunas na estruturação de equipes.

A PRLGrill (metalurgia básica) configura-se na classificação tecnológica da OCDE como de média-baixa intensidade, no Sistema PPV está na fase "Caminho da Escola" e na pontuação de Agregação Tecnológica atingiu o score (3,2).

Este score remete a PRLGrill no processo de incubação numa posição de know why moderado, apresentando processos formais e capacidade de produção consolidada; o conhecimento migrando para patamares explícitos, com liderança e rotinas consolidadas.

A Micro Injeção é uma empresa do setor de plásticos (média-baixa intensidade tecnológicaOCDE), no sistema de gestão PPV vive a etapa "Primeiros Passos", e seu score (pontuação) de Agregação Tecnológica (1,3). 
Este score indica que a Micro Injeção está ainda no primeiro estágio de conhecimento tecnológico de Bohn, fase de identificação, num patamar de Awareness avançado, aprender fazendo, inovar por imitação. Ausência de regras e normas de certificação e baixa relevância do trabalho em equipe (ações conjuntas).

A startup Ser Leve opera no ramo de alimentos (grãos) e pertence ao grupo de baixa intensidade tecnológica. No sistema PPV está vivendo a fase "Articulando Conhecimentos” e o score de Agregação Tecnológica registrou 1,2 pontos.

O estágio de conhecimento tecnológico da empresa start-up configura-se como "Awareness" moderado: falta conhecimento necessário para criar e usar a tecnologia. Típico de projetos em fase de desenvolvimento de processo e produto. O Conhecimento é tácito e há ausência do trabalho em equipe.

A MS Ferramentaria caracteriza-se na classificação da OCDE como de Média-baixa intensidade tecnológica e no processo de incubação desenvolve a fase articulando conhecimentos e cujo estágio atual de agregação tecnológica atingiu score 3,1.

Este score corresponde na escala de Bohn ao estágio de Know why incipiente, certas variáveischave estão em estágios médios de conhecimento com potencial para avanços rápidos na curva de aprendizagem.

Cumpre ainda destacar que na tabela 5, a coluna 3 representa as medidas do raio dos grafos construídos a partir das respostas de cada startup às indagações objeto da tabela 4 .

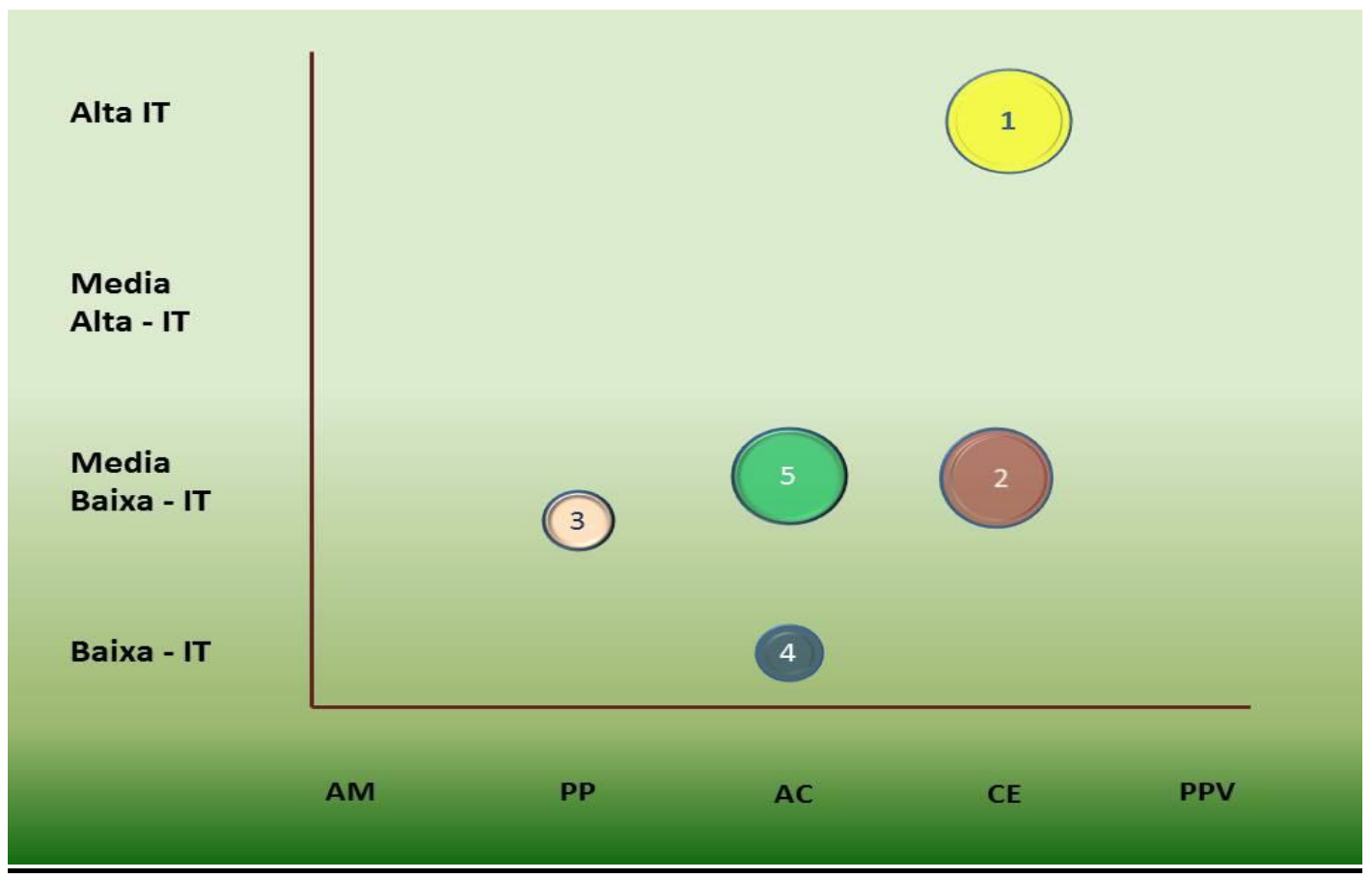

Figura 2: Matriz Dimensional de Segregação tecnológica. 
A figura 2 é uma matriz representativa do posicionamento das empresas nascentes sustentado no desempenho das variáveis que ilustram o estágio atual do processo de incubação. No eixo vertical é apresentada a escala ascendente de intensidade tecnológica desenvolvida pela OCDE, e no eixo horizontal estão representadas as fases do sistema PPV, que conforme já discutido anteriormente, é um sistema de gestão estruturante do processo de incubação, que promove na empresa nascente o desenvolvimento e avaliação simultânea de três variáveis: ciclo de vida, maturidade e competências. Por fim, no I quadrante do sistema gráfico contextualizado na figura 2 tem-se o posicionamento de agregação tecnológica de cada empresa nascente balizado por medidas oriundas da tabela 5. A representação da agregação tecnológica é marcada por circunferências, nas quais a área é diretamente proporcional ao nível de intensidade do agregado tecnológico (conhecimento materializado).

\section{CONSIDERAÇÕES FINAIS}

Os resultados deixaram evidente que a metodologia proposta permite segregar e organizar diferentes níveis de empresas nascentes pelo seu grau de intensidade tecnológica, permitindo aferir estágios de agregação de conhecimento em incubadoras de empresas de base tecnológica.

Dentro dessa lógica, a metodologia aqui desenvolvida e aplicada torna-se uma construção teórica importante para o entendimento das "situações reais" que envolvem as práticas da vida em ambientes inovativos (incubadoras de empresas), nos quais o conhecimento é a principal matéria prima de produção e, portanto, representativo de uma variável extremamente complexa, e de difícil mensuração.

$\mathrm{Na}$ confrontação do modelo (tabelas 4 e 5, e fig. 2) ao caso da ITAG, foram reunidas as evidências que permitiram tratar a Questão Central deste trabalho que tinha no seu escopo construir um instrumental de indicadores que não são abordados em nenhum modelo encontrado na literatura especializada, sendo, esta, uma das contribuições originais deste trabalho.

Desta feita, o desenvolvimento deste modelo vem preencher um gap relevante na gestão de incubadoras de base tecnológica, visto que, como os modelos tradicionais de gestão aplicados em tais ambientes se restringem à análise do ciclo de vida da empresa nascente tornam-se incapazes de quantificar os estágios de conhecimento e a aplicação (materialização) de tais conhecimentos ao projeto da empresa nascente.

Considerando o presente instrumental desenvolvido, o qual tem o potencial de avanços rápidos utilizando-se de algoritmos matemáticos e instrumentos de tecnologia da informação, dá-se um passo

Revista de Administração e Inovação, São Paulo, v. 12, n.1, p.227-247, jan./mar. 2015. 
importante na capacidade de quantificar variáveis eminentemente subjetivas, dando-lhes representatividade numérica, e tornando-as, assim, mais representativas à missão da incubadora no desenvolvimento da empresa nascente.

\section{REFERÊNCIAS}

ANPROTEC - Estudo, Análise e Proposições sobre as Incubadoras de Empresas no Brasil - relatório técnico / Associação Nacional de Entidades Promotoras de Empreendimentos Inovadores. Ministério da Ciência, Tecnologia e Inovação. - Brasília : ANPROTEC, 2012

BOHN, R.E. From art to science in manufacturing. the evolution of technology. Foundation and trends in technology, information and operations. v.2 .n. 1.p. 1-82. 2005

DAMIÃO, D.; GRAÇA, C. A.. O SISTEMA PPV NA GESTÃO ESTRATÉGICA DO PROCESSO DE INCUBAÇÃO. O CASO DA INCUBADORA TECNOLÓGICA AGENDE GUARULHOS. In: XXI Seminário Nacional de Parques Tecnológicos e Incubadoras. Associação Nacional de Entidades Promotoras de Empreendimentos Inovadores (Anprotec) - 2011. Porto Alegre.

FAPESP. Indicadores de Ciência, Tecnologia e Inovação em São Paulo - Brasil, 2010, Volume 1, Fapesp (50 Anos).

FIATES, J. E. A,; SOUZA, Antônio Rogério de.; CHIERIGUINI, Tony.; PRIM, Carlos Henrique.; UENO, Alexandre Takeshi. Modelo de aceleração do Desenvolvimento de Empresas de Base Tecnológica: da geração da idéia a consolidação do negócio. LOCUS CIENTÍfICO, 2008. vol. 2 n 02 , pags. $54-62$

FURTADO, A.T.; CAMILLO, E.V., A Contribuição do IBI para os indicadores de inovação nas empresas, Revista Eletrônica de Jornalismo Científico, São Paulo-SP, 2008.

GEHANY, R. Ray. Management of Technology and Operations. New York: John Wiley \& Sons, Inc. 1998.

MONTOBBIO, F.; RAMPA, F. The impact of technology and structural change on export performance in nine developing countries. Elsevier, v. 33, n. 4, p. 527-547, 2005. Disponível em: <http://ideas.repec.org/s/eee/wdevel.html>.

NONAKA, I. \& TAKEUCHI, H.. Criação do conhecimento na empresa. Rio de Janeiro: Campus, 1997.

OQUIST, P. The epistemology of action research. Acta Sociologica, v. 21, n. 2, p. 143-163, 1978. http://dx.doi.org/10.1177/000169937802100204 [ Links ]

OCDE - SCIENCE, TECHNOLOGIE ET INDUSTRIE - Tableau de Bord d'Indicateurs: OCDE, 1997.

SLACK, N. et al. Administração da Produção, Editora Atlas, 1. ed. 1997; $3^{\text {a }}$ tiragem, São Paulo-SP, 1997.

Revista de Administração e Inovação, São Paulo, v. 12, n.1, p.227-247, jan./mar. 2015. 
THIOLLENT, M. Metodologia da pesquisa-ação. 15. ed. São Paulo: Cortez, 2007. [Links]

UNCTAD (2002). Trade and Development Report, 2002. New York and Geneva, 2002.

UNCTAD. World investment report. New York and Geneva: Unit//ed Nations, 2002a.

. Trade and development report. New York and Geneva: United Nations, 2002b./ http://www.geo-aqui.com/products/intensidade-tecnologica/ (acesso: 15/12/12)

VERRI, L.B., Disponível em: http://en.wikipedia.org/wiki/Technology_readiness_level (acesso: 10/11/12)

ZARIFIAN, Philippe. Objetivo competência: por uma nova lógica. São Paulo: Atlas, 2001.

\title{
METHODOLOGY FOR CONTROL OF TECHNOLOGY AGGREGATION IN THE INCUBATION PROCESS. THE EXPERIENCES OF THE AGENDE GUARULHOS TECHNOLOGY INCUBATOR, BRAZIL - 2013
}

\begin{abstract}
The success of emerging companies in the U.S. in the form of incubates in sectors of high technological intensity generated spillovers that showed to emerging economies can accelerate development through the construction locally such environments conducive to innovation. Particularly in Brazil, despite considering the unquestionable advances in the process of transfer of technological knowledge produced and materialized in such environments are still two latent structural gaps in this process: i) absence of models management, incorporating the impact variables in the process of incubator management, ii) tools to specifically measure the level of technological intensity of each project, considering the aggregation of knowledge and applicability. This paper offers an instrumental from the second challenge, since it allows measuring the level of technological intensity, the level of maturity and competence of companies and their state of aggregation of evolution of technical knowledge applied to your business.
\end{abstract}

Key-words: Incubators; Aggregation Technology; Innovation; Guarulhos.

Data do recebimento do artigo: 25/04/2014

Data do aceite de publicação: 20/03/2015

Revista de Administração e Inovação, São Paulo, v. 12, n.1, p.227-247, jan./mar. 2015. 